\title{
Green ultrasound-assisted extraction of anthocyanin and phenolic compounds from purple sweet potato using response surface methodology $* *$
}

\author{
Zhenzhou Zhu ${ }^{1}$, Qingyan Guan ${ }^{1}$, Ying Guo ${ }^{1}$, Jingren He ${ }^{1}$, Gang Liu ${ }^{1}$, Shuyi Li ${ }^{1}$, Francisco J. Barba ${ }^{2}$, \\ and Michel Y. Jaffrin ${ }^{3}$
}

\begin{abstract}
${ }^{1}$ School of Food Science and Engineering, Wuhan Polytechnic University, 430023 Wuhan, China
${ }^{2}$ Faculty of Pharmacy, Nutrition and Food Science Area, University of Valencia,

Avda.Vicent Andrés Estellés, s/n 46100 Burjassot, Valencia, Spain

${ }^{3}$ UMR 7338, Technological University of Compiegne, 60205 Compiegne Cedex, France
\end{abstract}

Received June 22, 2015; accepted November 16, 2015

A b s t r a c t. Response surface methodology was used to optimize experimental conditions for ultrasound-assisted extraction of valuable components (anthocyanins and phenolics) from purple sweet potatoes using water as a solvent. The Box-Behnken design was used for optimizing extraction responses of anthocyanin extraction yield, phenolic extraction yield, and specific energy consumption. Conditions to obtain maximal anthocyanin extraction yield, maximal phenolic extraction yield, and minimal specific energy consumption were different; an overall desirability function was used to search for overall optimal conditions: extraction temperature of $68^{\circ} \mathrm{C}$, ultrasonic treatment time of $52 \mathrm{~min}$, and a liquid/solid ratio of 20 . The optimized anthocyanin extraction yield, phenolic extraction yield, and specific energy consumption

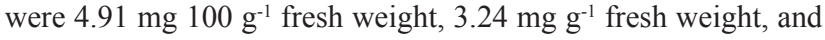
$2.07 \mathrm{kWh} \mathrm{g}^{-1}$, respectively, with a desirability of 0.99 . This study indicates that ultrasound-assisted extraction should contribute to a green process for valorization of purple sweet potatoes.

K e y w o r d s: purple sweet potato, ultrasound, anthocyanin, phenolic, extraction

\section{INTRODUCTION}

Sweet potatoes crops are important for food and feed, due to their high content in dietary fibres, minerals, vitamins, and antioxidants (Teow et al., 2007). Compared to those of white, yellow, or orange potatoes, purple sweet potatoes (PSP) contain an important amount of phenolics and anthocyanins (Wang et al., 2011). Thus, they are identified as a potential source of functional food ingredients (Bovell-Benjamin, 2007).

\footnotetext{
*Corresponding author e-mail: francisco.barba@uv.es zhenzhouzhu@126.com

**The authors appreciate the International Cooperation Research Funding granted by the Ministry of Science and Technology of China (2014DFG32310) and the support from the National Natural Science Foundation of China (31371727).
}

Valuable compounds (phenolics and anthocyanins) in PSP extracts have various functional abilities, such as antioxidant (Zhang et al., 2010), hepato-protective (Hwang et al., 2011), and memory enhancing properties. Conventionally, extraction of anthocyanins and phenolics with desirable yields has been carried out with solvents such as methanol, ethanol, and ethanol in hydrochloric acid medium (Pedro et al., 2015). For example, although anthocyanins are soluble in water, researchers observed that ethanol and methanol PSP extracts had approximately 3-4 times higher values of anthocyanins compared to water extracts from (Bridgers et al., 2010). Currently, ethanol and organic acids are preferable because they are less toxic than methanol and hydrochloric acid (Escribano-Bailón et al., 2004). However, these organic solvents are still considered toxic and hazardous to the environment.

Thus, it is important to investigate the technology of anthocyanin and phenolic extraction from PSP with more environmental-friendly solvents (eg water). Recovery of high-added value compounds from plant food materials usually involves 5 stages: macroscopic pre-treatment, macro- and micro-molecule separation, extraction, isolation and purification, and production formation (Galanakis, 2012). To reach the ultimate goal of:

- maximizing the yield of the target compounds, - suiting the demands of industrial processing,

(C) 2016 Institute of Agrophysics, Polish Academy of Sciences 
- clarifying the high added-value ingredients from impurities and toxic compounds,

- avoiding deterioration and loss of functionality during processing, and

- ensuring the food grade nature of the final product, the application of emerging technologies has been investigated over the last years (Deng et al., 2014; Galanakis 2012, 2013).

Among the most frequently used emerging technologies, ultrasound-assisted extraction (UAE) has been confirmed as one of the most economic and efficient extraction methods for recovery of valuable compounds, especially for extraction purposes (Galanakis, 2012; Galanakis and Schieber, 2014).

Ultrasound-assisted extraction is a novel technology based on a cavitation effect. Ultrasound wave propagation in the liquid phase causes extreme effects, especially under low frequencies of ultrasonic waves (between 20 and $100 \mathrm{kHz}$ ). The propagation causes alternating pressure and leads to compression of cavitational bubbles at high pressure and rarefaction of cavitational bubbles at low pressure. When these cycles are repeated, the bubbles implode and lead to damage of plant cell walls (Koubaa et al., 2015; Zinoviadou et al., 2015; Šic Žlabur et al., 2015). Thus, the cavitation encourages biomass diffusion, cell disruption, and solvent penetration (Galanakis, 2013; Kobus, 2008; Lagnika et al., 2014; Roselló-Soto et al., 2015).

Among other novel extraction techniques, ultrasound is more favourable in terms of lower temperature conditions of extraction and lower operation costs. Ultrasound has been applied in various research studies for intensification of functional compound extraction (Chemat and Khan, 2011; González-Centeno et al., 2014; Roselló-Soto et al., 2014). For example, UAE was applied to recover polyphenols, especially anthocyanins from blackberries and grape pomace (Barba et al., 2015a; 2015b; Corrales et al., 2008; González-Centeno et al., 2014) with promising results. Therefore, at this stage of development, it is interesting to investigate extraction of valuable compounds from PSP with ultrasound treatment.

Previous extraction tests showed that factors such as the solvent amount, extraction temperature, and time had a significant influence on the extraction yield. The combination of these factors and determination of the optimal conditions are important to obtain a suitable yield of targeted compounds. In order to obtain optimal extraction conditions with limited experiments, response surface methodology (RSM) is usually applied for optimization of the extraction process. It is an effective statistical tool for the optimization of multiple variables and prediction of best performance conditions with a minimum number of experiments.

Response surface methodology (RSM) is widely used in food industry and other related fields (Iqbal et al., 2013), especially for extraction of valuable compounds, where interactions exist between processing factors (Cai et al.,
2012; Fang et al., 2014; Lai et al., 2014; Tabaraki et al., 2012). For example, in the case of PSP valorization, Ahmed et al. (2011) optimized extraction conditions (drying temperature, citric acid concentration, and soaking time) for isolation of anthocyanins and phenolics from PSP using RSM with a face-centred cube design. Liu et al. (2013) used RSM to investigate aqueous two-phase extraction process conditions (liquid-solid ratio, concentration of ethanol and ammonium sulphate, and $\mathrm{pH}$ ) for extraction of anthocyanins from PSP.

In the present study, the applicability of ultrasound to recover anthocyanins and phenolics using water as a solvent was investigated. For this purpose, response surface methodology (Box-Behnken design) was used to evaluate the influence of ultrasound extraction temperature and time as well as the solid to liquid ratio and to determine the optimal extraction conditions to recover anthocyanins and phenolic compounds from purple sweet potato.

\section{MATERIALS AND METHODS}

Purple sweet potatoes (PSP) were purchased from a local market at Wuhan (China). The average weights of PSP were $100 \mathrm{~g}$. Fresh PSP were cut into slices with an average size of $1 \times 2 \times 50 \mathrm{~mm}$ for extraction purposes.

Ultrasound-assisted extraction was performed in a beaker $(500 \mathrm{ml}$ in a pulsed mode every $5 \mathrm{~s}$ treatment with a pause of $2 \mathrm{~s}$ ) with ultrasonic treatment generated by an ultrasonic processor FS-250N (Sonxi Ultrasonic Instrument, China) equipped with a sonotrode of $0.6 \mathrm{~cm}$ in diameter and wave amplitude of $60 \mu \mathrm{m}$. PSP slices with various weights (15-30 g) were placed into the beaker, and then $300 \mathrm{~g}$ of deionized water were added. The ultrasonic treatment power was $150 \mathrm{~W}$, with a frequency of $20 \mathrm{kHz}$. The extraction temperature was varied from 30 to $70^{\circ} \mathrm{C}$ and the ultrasonic treatment time was 30-60 min. In the extraction test, a hydrochloric acid solution with a concentration of $4 \%(\mathrm{v} / \mathrm{v})$ was added to obtain a $\mathrm{pH} \approx 1$ in the solvent, which is in the $\mathrm{pH}$ range of maximum anthocyanins colour stability, in order to prevent the degradation of these compounds (Lapornik et al., 2005). The extract was centrifuged for $5 \mathrm{~min}$ at $6000 \mathrm{~g}$ and pre-filtered through a mesh to remove pulps, then divided into portions and stored at the temperature of $-20^{\circ} \mathrm{C}$ until further analysis and use.

Response surface methodology (RSM) and, in particular a Box-Behnken design, was used in order to investigate the effects of three independent variables (extraction temperature $\left(\mathrm{T}, X_{1}\right)$, ultrasonic treatment time $\left(\mathrm{t}_{\mathrm{u}}, X_{2}\right)$, and the liquid/solid ratio $\left(\mathrm{L} / \mathrm{S}, X_{3}\right)$ ) on the extraction yield of anthocyanins $\left(Y_{a n}\right)$, phenolics $\left(Y_{p h}\right)$, and specific energy consumption $\left(E_{a n+p h}\right)$. Regression analysis was performed on the data obtained from the experiments. The experimental design and statistical analysis were performed using a Design-Expert Version 7.0.0 software. Coded and actual 
T a b l e 1. Independent variable values of the process and their corresponding levels

\begin{tabular}{lcccccc}
\hline \multirow{2}{*}{$\begin{array}{l}\text { Independent } \\
\text { variable }\end{array}$} & \multicolumn{2}{c}{ Symbol } & & \multicolumn{3}{c}{ Levels } \\
\cline { 2 - 3 } \cline { 5 - 6 } $\mathrm{T}\left({ }^{\circ} \mathrm{C}\right)$ & Actual & Coded & & -1 & 0 & 1 \\
$\mathrm{t}_{\mathrm{u}}(\mathrm{min})$ & $\mathrm{X}_{1}$ & $\mathrm{x}_{1}$ & & 30 & 50 & 70 \\
$\mathrm{~L} / \mathrm{S}$ & $\mathrm{X}_{2}$ & $\mathrm{x}_{2}$ & & 30 & 45 & 60 \\
\hline
\end{tabular}

$\mathrm{T}$ - temperature, $\mathrm{t}_{\mathrm{u}}-\mathrm{ultrasonic}$ treatment time, $\mathrm{L} / \mathrm{S}-$ liquid/solid ratio.

levels for process or independent variables are shown in Table 1 . The correspondence between coded and actual values can be obtained using the following formula (Eq. (1)):

$$
x_{i}=\frac{X_{i}-X_{i}^{0}}{\Delta X_{i}},
$$

where: $x_{i}$ is the coded value, $X_{\mathrm{i}}$ is the corresponding actual value, $X_{i}^{0}$ is the actual value in the centre of the domain, and $\Delta X_{i}$ is the variation amplitude around the mean value.

Experimental data for anthocyanin extraction and phenolic extraction were fitted to a quadratic model (Eq. (2)) and 2FI model (Eq. (3)), respectively. Data for specific energy were also fitted to a quadratic model and regression coefficients were calculated. The generalized model used in the response $(y)$ surface analysis was as follows:

$$
\begin{gathered}
y=b_{0}+b_{1} x_{1}+b_{2} x_{2}+b_{3} x_{3}+b_{12} x_{1} x_{2}+b_{23} x_{2} x_{3}+ \\
b_{13} x_{1} x_{3}+b_{11} x_{1}^{2}+b_{22} x_{2}^{2}+b_{33} x_{3}^{2} \\
y=b_{0}+b_{1} x_{1}+b_{2} x_{2}+b_{3} x_{3}+b_{12} x_{1} x_{2}+b_{23} x_{2} x_{3}+b_{13} x_{1} x_{3},
\end{gathered}
$$

where: $x_{1}, x_{2}$ and $x_{3}$ correspond to coded independent variables, namely, temperature, ultrasonic treatment time, and liquid/solid ratio, respectively. The $b_{n}$ values represent corresponding regression coefficients.

Five replicates at the centre of the design were used for estimating errors in the sum of the squares. The experiments were randomized in order to maximize the effects of unexplained variability in the observed responses due to extraneous factors. The experimental plan, along with the results, is presented in Table 2.

The responses of each independent variable are listed in Table 2. In order to ensure a good optimization model, a test of significance of the regression model and a test of lack-of-fit were performed. The F-value or p-value (also named 'Prob. $>$ F' value) was generally used to evaluate the significance of the model. The larger the magnitude of the F-value and correspondingly the smaller the 'p-value, the more significant is the model.
Anthocyanin content $\left(C_{a n}\right)$ was determined according to a pH-differential method based on colour change of anthocyanins with $\mathrm{pH}$ (Lee et al., 2005). For each sample, the absorbance was measured at $\mathrm{pH} 1.0$ and 4.5. The observed absorbance difference was proportional to the anthocyanin content. $C_{a n}\left(\mathrm{mg} \mathrm{l}^{-1}\right)$ was calculated according to Eqs (4) and (5):

$$
C_{a n}=\frac{A b s}{\varepsilon L} M W D 1000
$$

with

$A b s=\left(A_{541 \mathrm{~nm}}-A_{700 \mathrm{~nm}}\right) \mathrm{pH}_{1.0}-\left(A_{541 \mathrm{~nm}}-A_{700 \mathrm{~nm}}\right) \mathrm{pH}_{4.5}$,

where: $C_{a n}$ is the total anthocyanin content expressed as a cyanidin-3-glucoside equivalent (CGE) (mg CGE $\left.\mathrm{l}^{-1}\right)$, $A_{541}$ and $A_{700}$ are absorbancies at 541 and $700 \mathrm{~nm}$ respectively, $M W$ is cyanidin-3-glucoside molecular weight (449.2 $\left.\mathrm{g} \mathrm{mol}^{-1}\right), D$ is the dilution factor, $\varepsilon$ is cyanidin-3-glucoside molar absorptivity $\left(26,9001 \mathrm{~mol}^{-1} \mathrm{~cm}^{-1}\right), L$ is the measurement cell path length $(1 \mathrm{~cm}$ in the present study), and $10^{3}$ is the conversion factor from $\mathrm{g}$ to $\mathrm{mg}$. Anthocyanin extraction yield $\left(Y_{a n}\right)\left(\mathrm{mg} 100 \mathrm{~g}^{-1} \mathrm{fw}\right)$ was determined as follows Eq. (6):

$$
Y_{a n}=\frac{C_{a n} V}{m_{f w}} 100
$$

where: $V$ is the extracted volume (1), and $m_{f w}$ is the weight of fresh ( $f w)$ (g) PSP used.

Phenolic content $\left(C_{p h}\right)$ was determined by the FolinCiocalteu assay. The Folin-Ciocalteu reagent was prepared in our laboratory. Standard solutions with different concentrations from $0-0.1 \mathrm{mg} \mathrm{ml}^{-1}$ were made up using gallic acid. Portions of $1 \mathrm{ml}$ samples, $1 \mathrm{ml}$ Folin-Ciocalteu reagent, and $1.5 \mathrm{ml} 20 \%(\mathrm{w} / \mathrm{v}) \mathrm{Na}_{2} \mathrm{CO}_{3}$ were added successively to a glass tube, and then distilled water was added to increase the volume to $10 \mathrm{ml}$. The solution was placed in a dark place for $2 \mathrm{~h}$ at room temperature. The last absorbance was measued at $760 \mathrm{~nm}$. Phenolic content (mg GAE $~^{-1}$ ) was expressed as a gallic acid equivalent (GAE). Phenolic extraction yield $\left(Y_{p h}\right)\left(\mathrm{mg} \mathrm{GAE} \mathrm{g}^{-1} f w\right)$ was determined as follows (Eq. (7)): 
T a b l e 2. Response surface methodology (RSM) design and its experimental values

\begin{tabular}{|c|c|c|c|c|c|c|}
\hline \multirow[b]{2}{*}{ Run } & \multicolumn{3}{|c|}{ Independent variables } & \multicolumn{3}{|c|}{ Response variables } \\
\hline & $\begin{array}{c}\text { Temperature } \\
\left({ }^{\circ} \mathrm{C}\right) \\
X_{1}\left(x_{1}\right)\end{array}$ & $\begin{array}{l}\text { Ultrasonic time } \\
(\min ) \\
X_{2}\left(x_{2}\right)\end{array}$ & $\begin{array}{c}\text { Liquid } / \text { solid } \\
\text { ratio } \\
X_{3}\left(x_{3}\right)\end{array}$ & $\begin{array}{c}Y_{a n} \\
\left(\mathrm{mg} 100 \mathrm{~g}^{-1} f w\right)\end{array}$ & $\begin{array}{c}Y_{p h} \\
\left(\mathrm{mg} \mathrm{g}^{-1} f w\right)\end{array}$ & $\begin{array}{c}E_{a n+p h} \\
\left(\mathrm{kWh} \mathrm{g}^{-1}\right)\end{array}$ \\
\hline 1 & $30(-1)$ & $30(-1)$ & $15(0)$ & 1.22 & 1.32 & 2.82 \\
\hline 2 & $70(+1)$ & $45(0)$ & $10(-1)$ & 4.02 & 1.33 & 2.78 \\
\hline 3 & $50(0)$ & $45(0)$ & $15(0)$ & 3.77 & 1.71 & 3.26 \\
\hline 4 & $50(0)$ & $45(0)$ & $15(0)$ & 3.19 & 1.76 & 3.15 \\
\hline 5 & $70(-1)$ & $45(0)$ & $20(+1)$ & 4.50 & 2.90 & 2.55 \\
\hline 6 & $50(0)$ & $30(-1)$ & $20(+1)$ & 4.24 & 2.66 & 1.85 \\
\hline 7 & $50(0)$ & $45(0)$ & $15(0)$ & 3.82 & 1.72 & 3.20 \\
\hline 8 & $50(0)$ & $30(-1)$ & $10(-1)$ & 3.19 & 1.01 & 2.39 \\
\hline 9 & $50(0)$ & $45(0)$ & $15(0)$ & 3.78 & 2.19 & 2.52 \\
\hline 10 & $50(0)$ & $60(+1)$ & $20(+1)$ & 3.78 & 2.27 & 4.34 \\
\hline 11 & $50(0)$ & $45(0)$ & $15(0)$ & 4.05 & 2.12 & 2.61 \\
\hline 12 & $30(-1)$ & $45(0)$ & $20(+1)$ & 3.22 & 1.99 & 3.70 \\
\hline 13 & $70(+1)$ & $30(-1)$ & $15(0)$ & 2.82 & 1.39 & 2.65 \\
\hline 14 & $30(-1)$ & $60(+1)$ & $15(0)$ & 0.73 & 0.75 & 9.86 \\
\hline 15 & $70(+1)$ & $60(+1)$ & $15(0)$ & 4.96 & 3.08 & 2.40 \\
\hline 16 & $30(-1)$ & $45(0)$ & $10(-1)$ & 1.12 & 0.70 & 5.24 \\
\hline 17 & $50(0)$ & $60(+1)$ & $10(-1)$ & 2.75 & 0.90 & 5.38 \\
\hline
\end{tabular}

$$
Y_{p h}=\frac{C_{p h} V}{m_{f w}}
$$

The energy consumption per gram of extracted anthocyanins and phenolics (specific energy, $\left.E_{a n+p h}\right)\left(\mathrm{kWh} \mathrm{g}^{-1}\right)$ is represented by Eq. (8):

$$
E_{a n+p h}=\frac{Q}{m_{a n+p h}},
$$

where: $Q$ is the energy consumed for ultrasonic treatment $(\mathrm{kWh})$, and $m_{a n+p h}$ is the weight $(\mathrm{g})$ of anthocyanins and phenolics extracted.

\section{RESULTS AND DISCUSSION}

The combined effect of the extraction temperature, ultrasonic treatment time, and liquid/solid ratio on the anthocyanin extraction yield is shown in Fig.1. The analysis of variance (ANOVA) for the RSM model is shown in Table 3. As can be seen in the figure and table, all the stu- died factors had a significant influence on the anthocyanin extraction yield ie a significant increase in the recovery of anthocyanins with the elapse of ultrasonic extraction time when temperature was increased (Fig. 1a).

Although some previous studies have demonstrated negative effects of high temperatures $\left(>60^{\circ} \mathrm{C}\right.$ ) (Buckow et al., 2010; Kechinski et al., 2010) on anthocyanin stability, the increase in anthocyanin yield with augmented extraction temperatures could be explained by multiple effects of temperature on the mass-transfer process such as improved diffusion, denaturation of the plant matrix, and improvement of solvent characteristics in terms of penetration and solubility of anthocyanins. Ultrasonic treatment combined with heating can induce the formation of localized micro fractures in cell walls, thus facilitating release of anthocyanins (Barba et al., 2015a, 2015b), which are mainly found in the upper cell layers of the hypodermis.

Moreover, the liquid-to-solid ratio also played an important role in the recovery of anthocyanins. At a higher liquid/solid ratio, the anthocyanin concentration gradient 


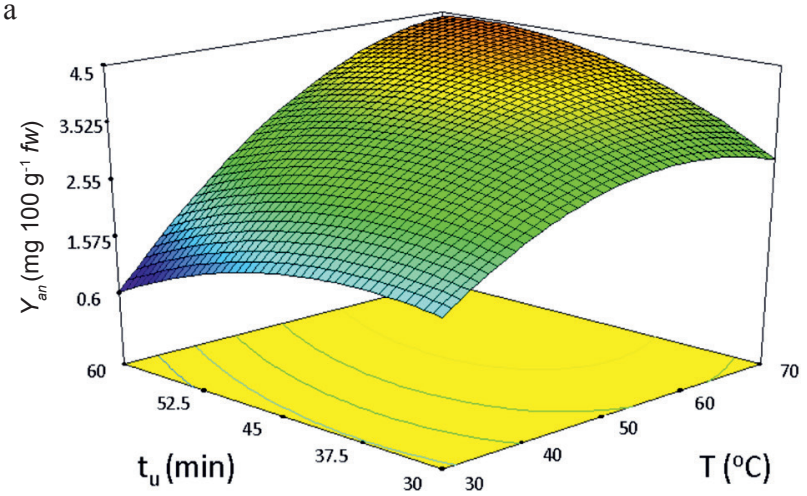

$\mathrm{b}$
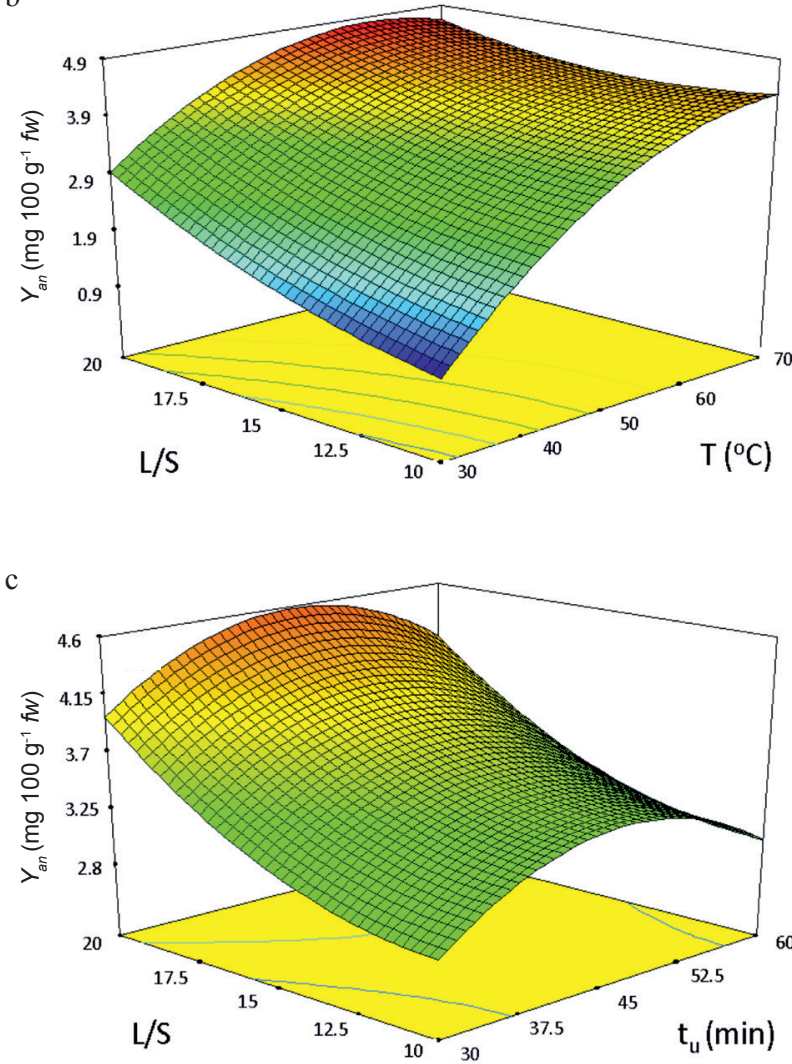

Fig. 1. Response surface plots showing the operating parameter effects on anthocyanin extraction yield $\left(Y_{a n}\right): \mathrm{a}-Y_{a n} v s$. T and $\mathrm{t}_{\mathrm{u}}$ at fixed $\mathrm{L} / \mathrm{S}$ of $15, \mathrm{~b}-Y_{a n} v s$. T and $\mathrm{L} / \mathrm{S}$ at fixed $\mathrm{t}_{\mathrm{u}}$ of $45 \mathrm{~min}, \mathrm{c}-Y_{a n}$ vs. $\mathrm{t}_{\mathrm{u}}$ and $\mathrm{L} / \mathrm{S}$ at fixed $\mathrm{T}$ of $50^{\circ} \mathrm{C}, f w-$ fresh weight.

is more important between the solid phase and the liquid phase, leading to an improved diffusion process and a higher anthocyanin yield (Fig. 1b).

On the other hand, the anthocyanin extraction yield first increased slightly when the ultrasonic treatment time was augmented, reaching a plateau after $45 \mathrm{~min}$ (Fig. 1c). However, longer ultrasonic treatment times led to a decrease in anthocyanin recovery. Due to the cavitation effect, an appropriate ultrasonic treatment could intensify solute extraction from plant matrix. As confirmed by other investigations, a prolonged ultrasonic treatment at a higher temperature may induce chemical decomposition of anthocyanins (Ramic et al., 2015; Tiwari et al., 2010).

According to the data shown in Table 2, amongst the experiments carried out in the present study, the experiment at the extraction temperature of $70^{\circ} \mathrm{C}$, ultrasonic treatment time of $60 \mathrm{~min}$, and a liquid/solid ratio of 15 provided the highest anthocyanin extraction yield (4.96 mg $100 \mathrm{~g}^{-1} \mathrm{fw}$ ). In turn, the ultrasonic treatment $\left(30^{\circ} \mathrm{C}, 60 \mathrm{~min} / \mathrm{liquid} / \mathrm{solid}\right.$ ratio of 15$)$ led to the lowest anthocyanin extraction yield (0.73 mg $\left.100 \mathrm{~g}^{-1} \mathrm{fw}\right)$.

As shown in Table 2, the extraction conditions to obtain the highest $\left(3.08 \mathrm{mg} \mathrm{GAE} \mathrm{g}^{-1} \mathrm{fw}\right.$ ) and the lowest $(0.75 \mathrm{mg}$ GAE $\mathrm{g}^{-1} f w$ ) phenolic extraction yield among all the experiments performed were the same as those obtained for anthocyanin extraction yield. Figure 2 shows the 3D surface response plots, representing the complex interaction between extraction conditions on phenolic extraction yield. All factors (extraction temperature, ultrasonic treatment time and liquid/solid ratio) had a significant influence on phenolic recovery. However, the behaviour of phenolic compounds after ultrasonic treatments was different from that found for anthocyanin recovery. As can be seen in Fig. 2a, phenolic recovery did not increase when ultrasonic treatment time and temperature were augmented. These results are in close agreement with those found by González-Centeno et al. (2014) when they studied the effect of ultrasonic extraction time on the recovery of total phenolics and total flavonoids from grape pomace. This fact can be attributed to the high temperatures and high pressures that can be generated when the cavitation bubbles induced by ultrasound reach a critical size, thus accelerating dramatically the chemical reactivity into the medium and inducing the degradation of some thermolabile and easily oxidizable phenolic compounds.

However, when the effect of the liquid-to-solid ratio was plotted against the extraction temperature, a significant increase in phenolic recovery was found when the temperature was higher (Fig. 2b). The degradation of thermolabile and easily oxidizable polyphenols at prolonged ultrasonic treatment time may be compensated by additional extraction of other phenolic compounds. It should be noted that the effect of ultrasonic treatment time seems weaker than extraction temperature and liquid/solid ratio. Moreover, like previously reported by Wong et al. (2015), the liquidto-solid ratio had a significant influence on the recovery of phenolic compounds (Fig. 2c), giving the highest values when the liquid-to-solid ratio was 20. In this line, Spigno et al. (2007) and Cacace and Mazza (2003) also observed a significant increase in extracted compounds when higher liquid-to-solid ratios were used. For instance, the ultrasound-assisted extraction technology may be combined with other emerging purification technologies eg membrane filtration, to purify the phenolic compounds in the extracts (Galanakis et al., 2013). 
a

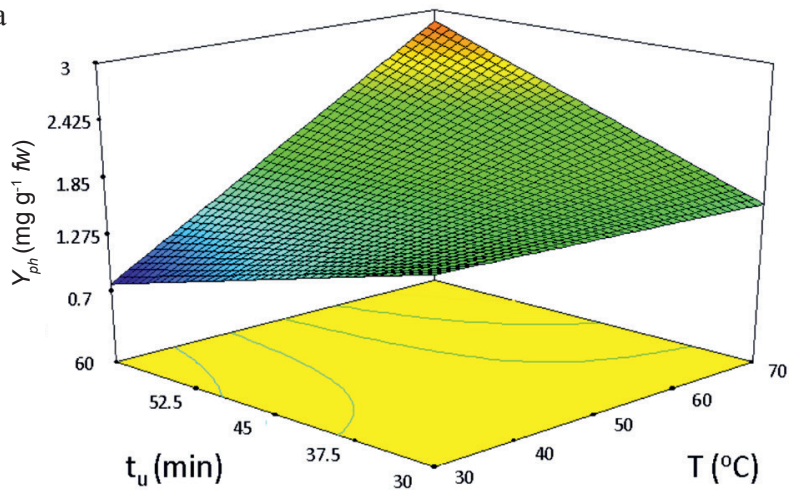

$\mathrm{b}$
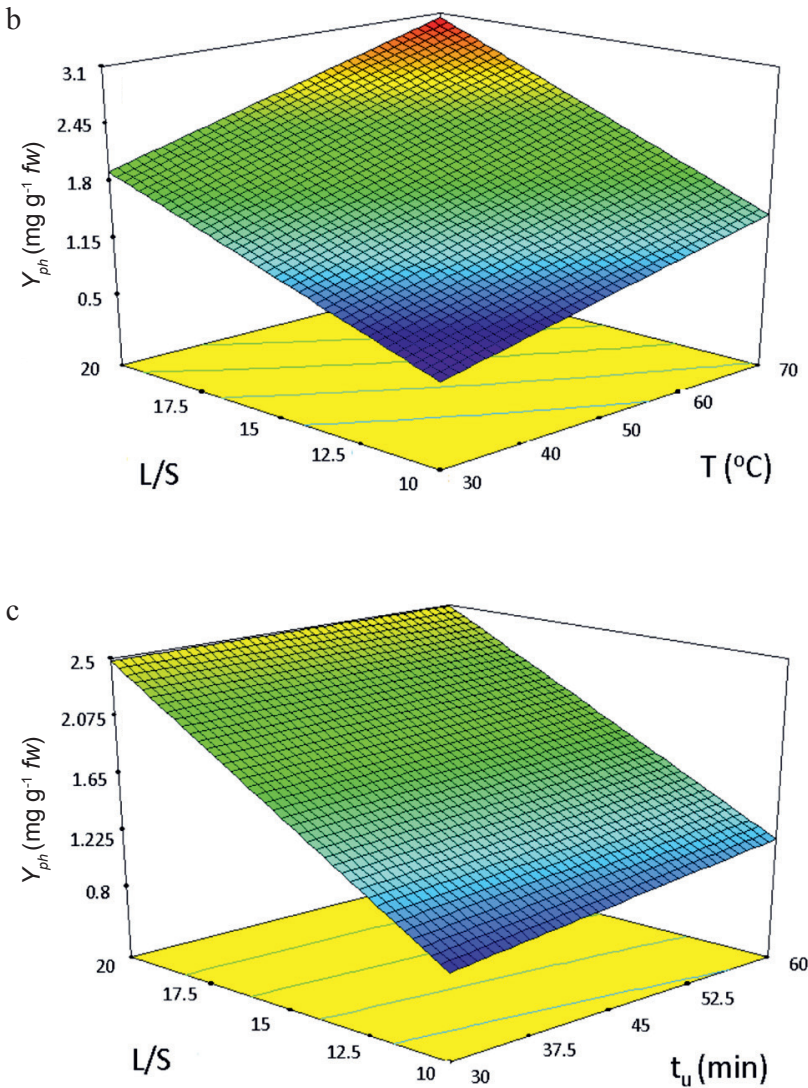

Fig. 2. Response surface plots showing the operating parameter effects on phenolic extraction yield $\left(Y_{p h}\right): \mathrm{a}-Y_{p h} v s$. T and $\mathrm{t}_{\mathrm{u}}$ at fixed L/S of 15, b $-Y_{p h} v s$. T and L/S at fixed $\mathrm{t}_{\mathrm{u}}$ of $45 \mathrm{~min}, \mathrm{c}-Y_{p h}$ vs. $\mathrm{t}_{\mathrm{u}}$ and $\mathrm{L} / \mathrm{S}$ at fixed $\mathrm{T}$ of $50^{\circ} \mathrm{C}, f w-$ fresh weight.

In the experimental range, the highest $\left(9.86 \mathrm{kWh} \mathrm{g}^{-1}\right)$ and lowest $\left(1.85 \mathrm{kWh} \mathrm{g}^{-1}\right)$ specific energies were obtained at an extraction temperature of $30^{\circ} \mathrm{C}$, an ultrasonic treatment time of $60 \mathrm{~min}$, a liquid/solid ratio of 15 , and an extraction temperature of $50^{\circ} \mathrm{C}$, ultrasonic treatment time of $30 \mathrm{~min}$ and liquid/solid ratio of 20 , respectively. The surface plots for the effect of extraction conditions on extraction yields and specific energy are presented in Fig. 3. It should be
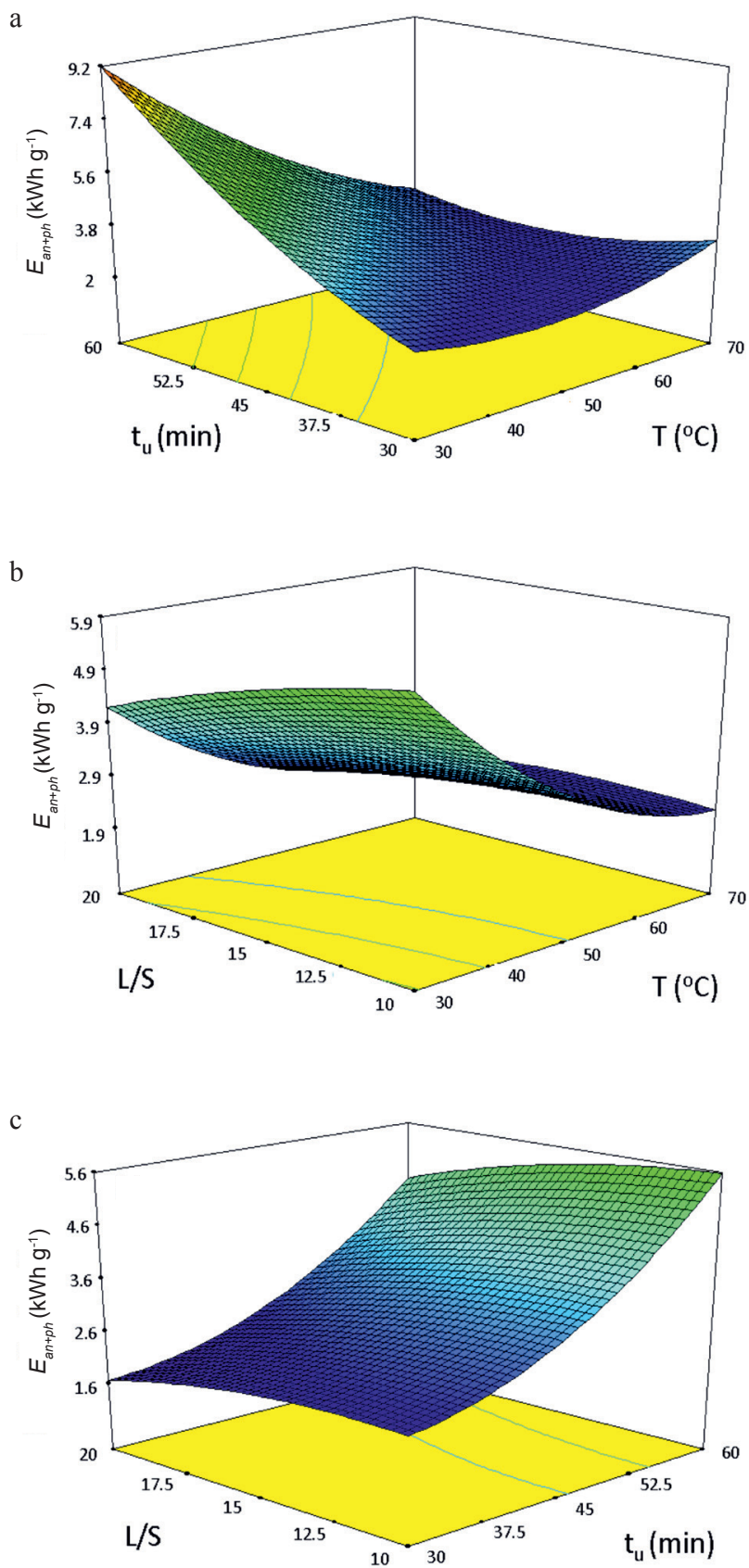

Fig. 3. Response surface plots showing the operating parameter effects on specific energy consumption $\left(E_{a n+p h}\right): \mathrm{a}-E_{a n+p h} v s$. T and $\mathrm{t}_{\mathrm{u}}$ at fixed $\mathrm{L} / \mathrm{S}$ of $15, \mathrm{~b}-E_{\mathrm{an}+\mathrm{ph}} v s$. T and $\mathrm{L} / \mathrm{S}$ at fixed $\mathrm{t}_{\mathrm{u}}$ of $45 \mathrm{~min}$, $\mathrm{c}-E_{a n+p h} v s . \mathrm{t}_{\mathrm{u}}$ and $\mathrm{L} / \mathrm{S}$ at fixed $\mathrm{T}$ of $50^{\circ} \mathrm{C}$.

noted that energy consumption was lower at the higher extraction temperature as the anthocyanin and phenolic extraction yields were considerably augmented, compared to low temperature extraction conditions. Moreover, a slight increase in specific energy consumption was also observed when the liquid/solid ratio increased from 10 to 20 . According to Fig. 3, the specific energy input increases with ultrasonic treatment time from 30 to $60 \mathrm{~min}$. 
T a b l e 3. Analysis of variance (ANOVA) for the RSM model of anthocyanin extraction yield $\left(Y_{a n}\right)$, phenolic extraction yield $\left(Y_{p h}\right)$, and specific energy $\left(E_{a n+p h}\right)$

\begin{tabular}{|c|c|c|c|c|c|c|}
\hline Source & Sum of squares & $\mathrm{df}$ & Mean square & F-value & \multicolumn{2}{|c|}{ p-value Prob. $>$ F } \\
\hline Model & 21.72 & 9 & 2.41 & 10.62 & 0.0026 & significant \\
\hline Residual & 1.59 & 7 & 0.23 & & & \\
\hline Lack of fit & 1.18 & 3 & 0.39 & 3.89 & 0.1112 & not significant \\
\hline Pure error & 0.41 & 4 & 0.10 & & & \\
\hline \multicolumn{7}{|l|}{$Y_{p h}^{* *}$} \\
\hline Model & 7.63 & 6 & 1.27 & 20.67 & 0.0002 & significant \\
\hline Residual & 0.82 & 10 & 0.061 & & & \\
\hline Lack of fit & 0.60 & 6 & 0.082 & 2.70 & 0.2956 & not significant \\
\hline Pure error & 0.22 & 4 & 0.030 & & & \\
\hline \multicolumn{7}{|l|}{$E_{a n+p h} * * *$} \\
\hline Model & 54.73 & 59 & 6.00 & 16.66 & 0.0008 & significant \\
\hline Residual & 2.74 & 7 & 0.36 & & & \\
\hline Lack of fit & 2.24 & 3 & 0.75 & 10.64 & 0.0584 & not significant \\
\hline Pure error & 0.50 & 4 & 0.07 & & & \\
\hline
\end{tabular}

T a b l e. 4. Optimum conditions, predicted and experimental values of responses

\begin{tabular}{|c|c|c|c|c|c|}
\hline \multirow{2}{*}{ Response } & \multicolumn{3}{|c|}{ Optimum ultrasonic-assisted extraction conditions } & \multicolumn{2}{|c|}{ Optimal values } \\
\hline & $\mathrm{T}\left({ }^{\circ} \mathrm{C}\right)$ & $\mathrm{t}_{\mathrm{u}}(\min )$ & $\mathrm{L} / \mathrm{S}$ & predicted & experimental \\
\hline$Y_{a n}^{\mathrm{M}}\left(\mathrm{mg} 100 \mathrm{~g}^{-1} f w\right)$ & 66 & 54 & 20 & 4.94 & - \\
\hline$Y_{p h}^{\mathrm{M}}\left(\mathrm{mg} \mathrm{g}^{-1} f w\right)$ & 68 & 57 & 20 & 3.34 & - \\
\hline$E_{a n+p h}^{\mathrm{m}}\left(\mathrm{kWh} \mathrm{g}^{-1}\right)$ & 43 & 30 & 19 & 1.60 & - \\
\hline$Y_{a n}^{\mathrm{M}}+Y_{p h}^{\mathrm{M}}+E_{a n+p h}^{\mathrm{m}}$ & 68 & 52 & 20 & $\begin{array}{r}4.91\left(Y_{a n}\right) \\
+3.24\left(Y_{p h}\right) \\
+2.07\left(E_{a n}\right)\end{array}$ & $\begin{aligned} & 4.72\left(Y_{a n}\right) \\
+ & 3.62\left(Y_{p h}\right) \\
+ & 2.45\left(E_{a n}\right)\end{aligned}$ \\
\hline
\end{tabular}

$\mathrm{M}$ - maximize, $\mathrm{m}$ - minimize.

Since maximal $Y_{a n}, Y_{p h}$, and minimal $E_{a n+p h}$ were achieved at different conditions, the RSM method was applied to optimize the operation conditions for all these responses (anthocyanin extraction yields, phenolic extraction yield, and specific energy).

The optimum conditions, predicted and experimental values for anthocyanin extraction yield $\left(Y_{a n}\right)$, phenolic extraction yield $\left(Y_{p h}\right)$, and specific energy $\left(E_{a n+p h}\right)$ are presented in Table 4. As shown in the table, the conditions to achieve a maximum $Y_{a n}$, maximal $Y_{p h}$ and minimal $E_{p h+a n}$ are different. Thus, a compromise between the conditions for these responses is needed. Indeed, as noted in previous investigations, the current challenge of ultrasound-assisted extraction is to establish conditions aiming at technoeconomical optimization prior to industrial exploitation (Galanakis, 2013). Thus a desirability function approach was used to achieve this purpose (Hu et al., 2005; Pinzauti et al., 1996). The overall desirability function is a multiplicative model of individual desirability as follows (Zhu et al., 2014): 


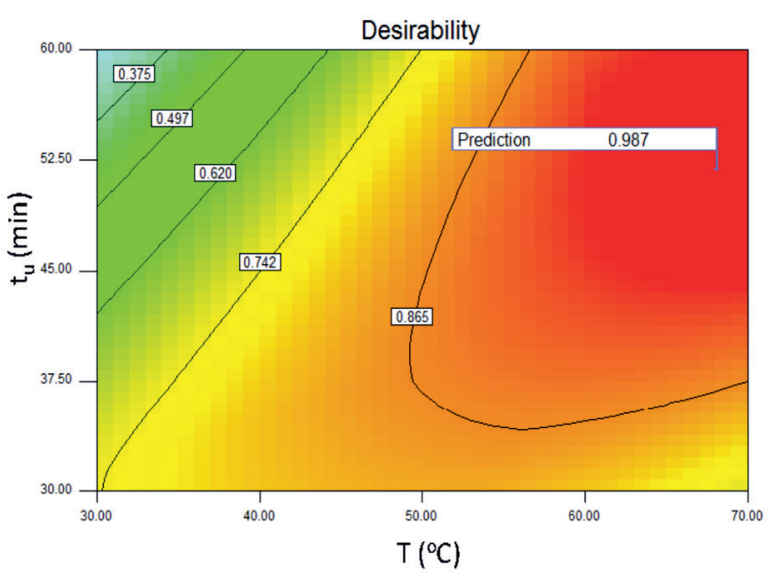

Fig. 4. Contour plots of desirability as a function of $T$ and $t_{u}$ at fixed L/S of 20.

$$
D=\left(d_{1} d_{2} \ldots d_{k}\right)^{1 / k}
$$

where: $D$ is the overall desirability, $0 \leq D \leq 1 ; d_{k}$ is the individual desirability for response number $k$ (in this study $k=3), 0 \leq d_{k} \leq 1$, and is defined by:

$$
d_{k}= \begin{cases}0, & \text { if } y_{k} \leq y_{k \min } \\ \frac{y_{k}-y_{k \min }}{y_{k \max }-y_{k \min }}, & \text { if } y_{k \min }<y_{k}<y_{k \max }, \\ 1, & \text { if } y_{k} \geq y_{k \max }\end{cases}
$$

where: $y$ is the value of response $\left(Y_{a n}, Y_{p h}\right.$ and $\left.E_{a n+p h}\right), y_{k \min }$ and $y_{k \text { max }}$ are the minimal and maximal acceptable value of $\mathrm{y}_{\mathrm{k}}$, respectively. In this study $\mathrm{y}_{k \text { min }}$ and $\mathrm{y}_{k \text { max }}$ were defined as the lowest and highest experimental values of $Y_{a n}, Y_{p h}$, and $E_{a n+p h}$, respectively. The individual desirability was found using Derringer approach (Derringer, 1980), which converts each response $\mathrm{y}_{k}$ into an individual desirability $d_{k}$ by using Eq. (10). The desirability scale ranges from 0 to 1 ; if the response is outside an acceptable range, it sets $d_{k}=0$, and if the response corresponds to the goal or target, it sets $d_{k}=1$.

The optimal conditions calculated from the regression equation were an extraction temperature of $68^{\circ} \mathrm{C}$, an ultrasonic treatment time of $52 \mathrm{~min}$, and a liquid/solid ratio of 20, respectively. The corresponding $Y_{a n}, Y_{p h}$, and $E_{a n+p h}$

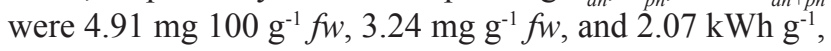
respectively, with a desirability of 0.99 . The overlay plot for the optimal region is presented in Fig. 4. The verification experiment under the optimal conditions was carried out in triplicate, and the results were close to the predicted values, as shown in Table 4, confirming the adequacy of the predicted models. According to the relevant literature, anthocyanin extraction yields from purple-fleshed sweet po- tatoes ranged from $9.5 \mathrm{mg} 100 \mathrm{~g}^{-1} \mathrm{fw}$ to $186.1 \mathrm{mg} 100 \mathrm{~g}^{-1} \mathrm{fw}$ (Ahmed et al., 2011; Bridgers et al., 2010; Brown et al., 2005), higher than current investigated results. However, this study is considered interesting, due to the effort to develop an environmental-friendly PSP valorization method with assistance of ultrasonic treatment. More efficient ultrasonic treatment equipment is being designed to improve extraction efficiency.

\section{CONCLUSIONS}

1. Response surface methodology using the BoxBehnken method was successfully applied to optimize extraction conditions for important valorization of functional components from purple sweet potatoes.

2. The ultrasound extraction temperature, treatment time, and liquid-to-solid ratio had an important influence on anthocyanin and phenolic extraction yields as well as on specific energy consumption.

3. An overall maximal anthocyanin extraction yield, phenolic extraction yield, and minimal specific energy consumption were predicted at a temperature of $68^{\circ} \mathrm{C}$, an ultrasonic treatment time of $52 \mathrm{~min}$, and a liquid to solid ratio of 20. Under these conditions, the experimental anthocyanin extraction yield, phenolic extraction yield, and specific energy were $4.72 \mathrm{mg} 100 \mathrm{~g}^{-1} f w, 3.62 \mathrm{mg} \mathrm{g}^{-1} f w$, and $2.45 \mathrm{kWh} \mathrm{g}^{-1}$, respectively, which were close to the predicted values.

4. This study showed the potential of ultrasound-assisted extraction as a promising green and sustainable process to recover anthocyanins and phenolic compounds from purple sweet potatoes.

\section{REFERENCES}

Ahmed M., Akter M.S., and Eun J.-B., 2011. Optimization conditions for anthocyanin and phenolic content extraction form purple sweet potato using response surface methodology. Int. J. Food Sci Nutr., 62(1), 91-96.

Barba F.J., Brianceau S., Turk M., Boussetta N., and Vorobiev E., 2015a. Effect of alternative physical treatments (ultrasounds, pulsed electric fields, and high-voltage electrical discharges) on selective recovery of bio-compounds from fermented grape pomace. Food Bioprocess Technol., 8(5), 1139-1148.

Barba F.J., Galanakis C.M., Esteve M.J., Frigola A., and Vorobiev E., 2015b. Potential use of pulsed electric technologies and ultrasounds to improve the recovery of high-added value compounds from blackberries. J. Food Eng., 167(Part A), 38-44.

Bovell-Benjamin A.C., 2007. Sweet potato: a review of its past, present, and future role in human nutrition. Adv. Food Nutr. Res., 52, 1-59.

Bridgers E.N., Chinn M.S., and Truong V.-D., 2010. Extraction of anthocyanins from industrial purple-fleshed sweetpotatoes and enzymatic hydrolysis of residues for fermentable sugars. Ind. Crop Prod., 32(3), 613-620. 
Brown C., Culley D., Yang C.-P., Durst R., and Wrolstad R., 2005. Variation of anthocyanin and carotenoid contents and associated antioxidant values in potato breeding lines. J. Am. Soc. Hort. Sci., 130(2), 174-180.

Buckow R., Kastell A., Terefe N.S., and Versteeg C., 2010. Pressure and temperature effects on degradation kinetics and storage stability of total anthocyanins in blueberry juice. J. Agr. Food Chem., 58(18), 10076-10084.

Cacace J. and Mazza G., 2003. Mass transfer process during extraction of phenolic compounds from milled berries. J. Food Eng., 59(4), 379-389.

Cai M., Wang S., and Liang H.-h., 2012. Optimization of ultrasound-assisted ultrafiltration of Radix astragalus extracts with hollow fiber membrane using response surface methodology. Sep Purif Technol., 100, 74-81.

Chemat F. and Khan M.K., 2011. Applications of ultrasound in food technology: processing, preservation and extraction. Ultrason Sonochem., 18(4), 813-835.

Corrales M., Toepfl S., Butz P., Knorr D., and Tauscher B., 2008. Extraction of anthocyanins from grape by-products assisted by ultrasonics, high hydrostatic pressure or pulsed electric fields: A comparison. Innovative Food Sci. Emerging Technol., 9(1), 85-91.

Deng Q., Zinoviadou K.G., Galanakis C.M., Orlien V., Grimi N., Vorobiev E., Lebovka N., and Barba F.J., 2014. The effects of conventional and non-conventional processing on glucosinolates and its derived forms, isothiocyanates: extraction, degradation, and applications. Food Eng. Rev., $7(3), 357-381$.

Derringer G., 1980. Simultaneous optimization of several response variables. J. Qual. Technol., 12, 214-219.

Escribano-Bailón M.T., Santos-Buelga C., and Rivas-Gonzalo J.C., 2004. Anthocyanins in cereals. J. Chromatogr. A, 1054(1), 129-141.

Fang X., Wang J., Wang Y., Li X., Zhou H., and Zhu L., 2014. Optimization of ultrasonic-assisted extraction of wedelolactone and antioxidant polyphenols from Eclipta prostrate L. using response surface methodology. Sep Purif Technol., $138,55-64$.

Galanakis C.M., 2012. Recovery of high added-value components from food wastes: conventional, emerging technologies and commercialized applications. Trends Food Sci. Technol., 26(2), 68-87.

Galanakis C.M., 2013. Emerging technologies for the production of nutraceuticals from agricultural by-products: a viewpoint of opportunities and challenges. Food Bioprod Process., 91(4), 575-579.

Galanakis C.M., Markouli E., and Gekas V., 2013. Recovery and fractionation of different phenolic classes from winery sludge using ultrafiltration. Sep. Purif. Technol., 107, 245-251.

Galanakis C.M. and Schieber A., 2014. Editorial. Food Res Int. 65, Part C, 299-300.

González-Centeno M.R., Knoerzer K., Sabarez H., Simal S., Rosselló C., and Femenia A., 2014. Effect of acoustic frequency and power density on the aqueous ultrasonic-assisted extraction of grape pomace (Vitis vinifera L.) A response surface approach. Ultrason Sonochem., 21(6), 2176-2184.

Hu Y.-Y., Zheng P., He Y.-Z., and Sheng G.-P., 2005. Response surface optimization for determination of pesticide multiresidues by matrix solid-phase dispersion and gas chromatography. J. Chromatogr. A, 1098(1), 188-193.
Hwang Y.P., Choi J.H., Choi J.M., Chung Y.C., and Jeong H.G., 2011. Protective mechanisms of anthocyanins from purple sweet potato against tert-butyl hydroperoxide-induced hepatotoxicity. Food Chem. Toxicol., 49(9), 2081-2089.

Iqbal M., Ahmad I., Hussain S., Khera R., Bokhari T., and Shehzad M., 2013. Optimization of pre-sowing magnetic field doses through RSM in pea. Int Agrophys., 27, 265-273.

Kechinski C.P., Guimarães P.V.R., Noreña C.P.Z., Tessaro I.C., and Marczak L.D.F., 2010. Degradation kinetics of anthocyanin in blueberry juice during thermal treatment. J. Food Sci., 75(2), C173-C176.

Kobus Z., 2008. Dry matter extraction from valerian roots (Valeriana officinalis L.) with the help of pulsed acoustic field. Int Agrophysics, 22, 133.

Koubaa M., Roselló-Soto E., Šic Žlabur J., Režek Jambrak A., Brnčić M., Grimi N., Boussetta N., and Barba F.J., 2015. Current and new insights in the sustainable and green recovery of nutritionally valuable compounds from Stevia rebaudiana Bertoni. J. Agr. Food Chem., 63(31), 68356846.

Lagnika C., Zhang M., Nsor-Atindana J., and Tounkara F., 2014. Extension of mushroom shelf-life by ultrasound treatment combined with high pressure argon. Int Agrophys., 28, 39-47.

Lai T.N.H., André C.M., Chirinos R., Nguyen T.B.T., Larondelle Y., and Rogez H., 2014. Optimisation of extraction of piceatannol from Rhodomyrtus tomentosa seeds using response surface methodology. Sep. Purif. Technol., 134, 139-146.

Lapornik B., Prošek M., and Wondra A.G., 2005. Comparison of extracts prepared from plant by-products using different solvents and extraction time. J. Food Eng., 71(2), 214-222.

Lee J., Durst R.W., and Wrolstad R.E., 2005. Determination of total monomeric anthocyanin pigment content of fruit juices, beverages, natural colorants, and wines by the $\mathrm{pH}$ differential method: collaborative study. J. Aoac. Int., 88(5), 1269-1278.

Liu X., Mu T., Sun H., Zhang M., and Chen J., 2013. Optimisation of aqueous two-phase extraction of anthocyanins from purple sweet potatoes by response surface methodology. Food Chem., 141(3), 3034-3041.

Pedro A.C., Granato D., and Rosso N.D., 2015. Extraction of anthocyanins and polyphenols from black rice (Oryza sati$v a$ L.) by modeling and assessing their reversibility and stability. Food Chem., 191, 12-20.

Pinzauti S., Gratteri P., Furlanetto S., Mura P., Dreassi E., and Phan-Tan-Luu R., 1996. Experimental design in the development of voltammetric method for the assay of omeprazole. J. Pharmaceut Biomed., 14(8), 881-889.

Ramic M., Vidovic S., Zekovic Z., Vladic J., Cvejin A., and Pavlic B., 2015. Modeling and optimization of ultrasoundassisted extraction of polyphenolic compounds from Aronia melanocarpa by-products from filter-tea factory. Ultrason Sonochem., 23, 360-368.

Roselló-Soto E., Barba F.J., Parniakov O., Galanakis C.M., Lebovka N., Grimi N., and Vorobiev E., 2014. High voltage electrical discharges, pulsed electric field, and ultrasound assisted extraction of protein and phenolic compounds from olive kernel. Food Bioprocess Technol., 8(4), 885-894. 
Roselló-Soto E., Galanakis C.M., Brnčić M., Orlien V., Trujillo F.J., Mawson R., Knoerzer K., Tiwari B.K., and Barba F.J., 2015. Clean recovery of antioxidant compounds from plant foods, by-products and algae assisted by ultrasounds processing. Modeling approaches to optimize processing conditions. Trends Food Sci. Technol., 42(2), 134-149.

Šic Žlabur J., Voća S., Dobričević N., Brnčić M., Dujmić F., and Rimac Brnčić S., 2015. Optimization of ultrasound assisted extraction of functional ingredients from Stevia rebaudiana Bertoni leaves. Int Agrophys., 29, 231-237.

Spigno G., Tramelli L., and De Faveri D.M., 2007. Effects of extraction time, temperature and solvent on concentration and antioxidant activity of grape marc phenolics. J. Food Eng., 81(1), 200-208.

Tabaraki R., Heidarizadi E., and Benvidi A., 2012. Optimization of ultrasonic-assisted extraction of pomegranate (Punica granatum L.) peel antioxidants by response surface methodology. Sep. Purif Technol., 98, 16-23.

Teow C.C., Truong V.-D., McFeeters R.F., Thompson R.L., Pecota K.V., and Yencho G.C., 2007. Antioxidant activities, phenolic and $\beta$-carotene contents of sweet potato genotypes with varying flesh colours. Food Chem., 103(3), 829-838.

Tiwari B.K., Patras A., Brunton N., Cullen P.J., and O'Donnell C.P., 2010. Effect of ultrasound processing on anthocyanins and color of red grape juice. Ultrason Sonochem., 17(3), 598-604.
Wang S.-M., Yu D.-J., and Song K.B., 2011. Quality characteristics of purple sweet potato (Ipomoea batatas) slices dehydrated by the addition of maltodextrin. Hortic, Environ Biotechnol., 52(4), 435-441.

Wong W.H., Lee W.X., Ramanan R.N., Tee L.H., Kong K.W., Galanakis C.M., Sun J., and Prasad K.N., 2015. Two level half factorial design for the extraction of phenolics, flavonoids and antioxidants recovery from palm kernel byproduct. Ind. Crop Prod., 63, 238-248.

Zhang Z.-f., Lu J., Zheng Y.-I., Hu B., Fan S.-h., Wu D.-m., Zheng Z.-h., Shan Q., and Liu C.-m., 2010. Purple sweet potato color protects mouse liver against d-galactoseinduced apoptosis via inhibiting caspase-3 activation and enhancing PI3K/Akt pathway. Food Chem. Toxicol., 48(8), 2500-2507.

Zhu Z., Ladeg S., Ding L., Bals O., Nadji M.-M., Jaffrin M.Y., and Vorobiev E., 2014. Study of rotating disk assisted dead-end filtration of chicory juice and its performance optimization. Ind. Crop Prod., 53(0), 154-162.

Zinoviadou K.G., Galanakis C.M., Brnčić M., Grimi N., Boussetta N., Mota M.J., Saraiva J.A., Patras A., Tiwari B., and Barba F.J., 2015. Fruit juice sonication: Implications on food safety and physicochemical and nutritional properties. Food Res. Int., 77,743-752. 